\title{
Roles of yeast DNA polymerases $\delta$ and $\zeta$ and of Rev1 in the bypass of abasic sites
}

\author{
Lajos Haracska, ${ }^{1}$ Ildiko Unk, ${ }^{1}$ Robert E. Johnson, ${ }^{1}$ Erik Johansson, ${ }^{2}$ Peter M.J. Burgers, ${ }^{2}$ \\ Satya Prakash, ${ }^{1}$ and Louise Prakash ${ }^{1,3}$ \\ ${ }^{1}$ Sealy Center for Molecular Science, University of Texas Medical Branch, Galveston, Texas 77555-1061, USA; ${ }^{2}$ Department \\ of Biochemistry and Molecular Biophysics, Washington University School of Medicine, St. Louis, Missouri 63110, USA
}

\begin{abstract}
Abasic (AP) sites are one of the most frequently formed lesions in DNA, and they present a strong block to continued synthesis by the replicative DNA machinery. Here we show efficient bypass of an AP site by the combined action of yeast DNA polymerases $\delta$ and $\zeta$. In this reaction, Pol $\delta$ inserts an A nucleotide opposite the AP site, and Pol $\zeta$ subsequently extends from the inserted nucleotide. Consistent with these observations, sequence analyses of mutations in the yeast $C A N 1^{s}$ gene indicate that $\mathrm{A}$ is the nucleotide inserted most often opposite AP sites. The nucleotides C, G, and T are also incorporated, but much less frequently. Enzymes such as Rev1 and Pol $\eta$ may contribute to the insertion of these other nucleotides; the predominant role of Rev1 in AP bypass, however, is likely to be structural. Steady-state kinetic analyses show that Pol $\zeta$ is highly inefficient in incorporating nucleotides opposite the AP site, but it efficiently extends from nucleotides, particularly an A, inserted opposite this lesion. Thus, in eukaryotes, bypass of an AP site requires the sequential action of two DNA polymerases, wherein the extension step depends solely upon Polל, but the insertion step can be quite varied, involving not only the predominant action of the replicative DNA polymerase, Polס, but also the less prominent role of various translesion synthesis polymerases.
\end{abstract}

[Key Words: Abasic sites; mutagenic bypass; yeast; DNA polymerase $\delta$; DNA polymerase $\zeta]$

Received January 24, 2001; revised version accepted February 15, 2001.

Abasic (AP) sites represent one of the most frequently formed DNA lesions in eukaryotes, and it has been estimated that a human cell loses as many as $10^{4}$ purines per day from its genome (Lindahl and Nyberg 1972). In Saccharomyces cerevisiae, AP sites are efficiently repaired by the AP endonucleases encoded by the APN1 and $A P N 2$ genes. APN1 and APN2 provide alternate pathways for the removal of AP sites, and consequently, simultaneous inactivation of both the genes results in a dramatic decline in the efficiency to repair AP sites (Johnson et al. 1998).

If the AP sites are not removed by excision repair processes, they present a block to the replication machinery. During replication, AP sites can be bypassed either by a specialized mutagenic DNA polymerase, or by errorfree mechanisms such as recombination or a copy-choice type of DNA synthesis. In S. cerevisiae, genes in the $R A D 6$ epistasis group promote replication through DNA lesions (Prakash 1981). The REV1, REV3, and REV7 genes of this group are essential for UV-induced mutagenesis (Lawrence and Hinkle 1996), and these genes are also indispensable for mutagenesis induced by AP sites (Johnson et al. 1998). REV1 encodes a deoxycytidyl trans-

${ }^{3}$ Corresponding author.

E-MAIL lprakash@scms.utmb.edu; FAX (409) 747-8608.

Article and publication are at www.genesdev.org/cgi/doi/10.1101/ $\operatorname{gad} .882301$. ferase activity (Nelson et al. 1996a), and the REV3- and $R E V 7$-encoded proteins together form DNA polymerase $\zeta$ (Nelson et al. 1996b).

Although Pol $\zeta$ is absolutely required for damage-induced mutagenesis, and therefore for the mutagenic bypass of a variety of DNA lesions, our recent studies have indicated that on its own, Pol $\zeta$ bypasses UV lesions very inefficiently (Johnson et al. 2000a). This is because Pol $\zeta$ is very inefficient in inserting nucleotides opposite the $3^{\prime}$ $\mathrm{T}$ of a cis-syn thymine-thymine (T-T) dimer or a (6-4) $\mathrm{T}-\mathrm{T}$ photoproduct. Pol $\zeta$, however, efficiently extends from nucleotides placed opposite the $3^{\prime} \mathrm{T}$ of these lesions by another DNA polymerase (Johnson et al. 2000a). Because Rev1 can insert a C opposite the AP site (Nelson et al. 1996a), and because Rev1 is essential for mutagenesis induced by AP sites (Johnson et al. 1998), in principle, mutagenic bypass of AP sites could be subsumed by the combined action of Rev1 and Polc. However, we find that mutational inactivation of the Rev1 C-transferase activity has little effect on AP mutagenesis, and sequence analyses of mutations resulting from AP bypass indicate that in vivo, $\mathrm{C}$ is inserted rather infrequently opposite AP sites. These observations suggest that the C-transferase activity of Rev1 is not likely to have a predominant role in AP bypass.

In addition to the requirement of Rev1 and Pol $\zeta$, genetic studies in yeast have indicated a requirement of Pold for the mutagenic bypass of DNA lesions. A muta- 
tion, pol3-13, in the catalytic subunit of Pols confers a deficiency in UV mutagenesis (Giot et al. 1997), and deletion of POL32, which encodes a nonessential subunit

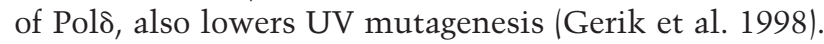
Because Polס is essential for the replication of both DNA strands and will be the first polymerase to encounter the DNA lesion, it could promote damage bypass by inserting a nucleotide opposite the lesion, which could then be extended by Pol $\zeta$. Here we provide evidence supporting such a role for Pols in AP bypass. From the pattern of mutations induced by AP sites in yeast, we infer that in vivo, $\mathrm{A}$ is the residue inserted most frequently opposite

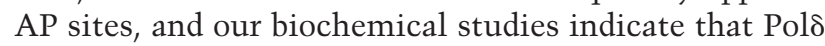
primarily inserts an A opposite the AP site. Efficient bypass of this lesion occurs when Pol $\delta$ is combined with Polל.

\section{Results}

Spectrum of $\mathrm{CAN}^{\mathrm{s}}$ to $\mathrm{can}^{\mathrm{r}}$ mutations resulting from AP bypass

To determine the mutational specificity of AP sites in vivo, we sequenced mutations resulting from their bypass in yeast cells treated with the alkylating agent methyl methanesulfonate (MMS). MMS alkylates the bases in DNA, particularly adenine at the N3 position (3MeA) and guanine at the N7 position (7MeG). The removal of alkylated bases by an $N$-methyl purine DNA glycosylase (Roy et al. 1994; Bjoras et al. 1995) results in an AP site that can be acted upon by the AP endonuclease activity of Apn1 or Apn2 proteins. We examined MMS-induced $C A N 1^{S}$ to $c a n 1^{r}$ forward mutations in the apn1s apn2s strain because the repair of AP sites is severely inhibited in this strain. Sequence analysis of a number of independent $\operatorname{can}^{r}$ mutations formed in the apn $1 \Delta$ apn $2 \Delta$ strain after MMS treatment indicated that $\sim 70 \%$ of these were base substitutions and $\sim 30 \%$ were +1 or -1 frameshift mutations (Table 1). The most frequent base substitutions were $\mathrm{G}: \mathrm{C}$ to $\mathrm{T}: \mathrm{A}$ transversions $(40 \%)$. Considering that the majority of AP sites arise from the loss of A or G residues, we calculate that A, C, $\mathrm{G}$, and $\mathrm{T}$ nucleotides were inserted opposite AP sites

Table 1. MMS induced can $1^{\mathrm{r}}$ mutations in the apn $1 \Delta$ apn2 $\Delta$ strain

\begin{tabular}{lc}
\hline Mutations & Number (frequency) \\
\hline A:T $\rightarrow$ T:A & $2(5 \%)$ \\
G:C $\rightarrow$ T:A & $16(40 \%)$ \\
G:C $\rightarrow$ C:G & $3(7.5 \%)$ \\
A $T \rightarrow$ G:C & $4(10 \%)$ \\
G:C $\rightarrow$ A:T & $3(7.5 \%)$ \\
+1 frameshifts & $7(17.5 \%)$ \\
-1 frameshifts & $5(12.5 \%)$ \\
\hline
\end{tabular}

Yeast cells were suspended in $0.05 \mathrm{M} \mathrm{KPO}_{4}(\mathrm{pH}$ 7) buffer, and treated with $0.08 \% \mathrm{MMS}$ for $20 \mathrm{~min}$ at $30^{\circ} \mathrm{C}$. Following termination of the reaction by the addition of an equal volume of $10 \%$ sodium thiosulfate, cells were spun down, resuspended in water, and plated on synthetic complete medium lacking arginine and supplemented with canavanine. with relative frequencies of $64 \%, 14 \%, 11 \%$, and $11 \%$, respectively. These observations indicate that, in vivo, incorporation of an A residue opposite the AP site is the major base substitution caused by this DNA lesion.

\section{The deoxycytidyl transferase activity of Rev1 is} dispensable for mutagenesis induced by AP sites

To assess the in vivo role of the deoxycytidyl transferase activity of Rev1 in mutagenic bypass of AP sites, we examined the effect of inactivation of this activity on mutagenesis induced by AP sites. For this purpose, we altered the Asp 467 and Glu 468 residues present in the highly conserved motif III consisting of serine, isoleucine, aspartate, and glutamate residues (SIDE) in Rev1 to alanines (Johnson et al. 1999). The analogous mutation in $\operatorname{Rad} 30$ inactivates the DNA polymerase activity (Johnson et al. 1999), and similarly, the rev1 $A l a^{467}$ $A 1 a^{468}$ mutation completely inactivated the deoxycytidyl transferase activity of Rev1 (data not shown). To determine whether Rev1 deoxycytidyl transferase activity was required for AP mutagenesis, the ability of the rev1 $A l a^{467}-A 1 a^{468}$ mutation to complement the rev1s mutation was examined. The wild-type or the mutant gene was expressed in yeast from the native $R E V 1$ promoter on a low-copy CEN plasmid. Yeast cells were treated with various concentrations of MMS, and the rates of forward mutations at the $C A N 1^{s}$ locus were examined. Whereas MMS-induced can $1^{r}$ mutations are completely abolished in the apn1s apn2s rev1s strain (Johnson et al. 1998), introduction of the rev1 $A 1 a^{467}-A 1 a^{468}$ mutant gene into this strain restored MMS-induced $\operatorname{can} 1^{r}$ mutations to the level seen in the apn1s apn2s strain (data not shown). Thus, although the Rev1 protein is absolutely required for damage-induced mutagenesis, its deoxycytidyl transferase activity is dispensable for mutagenesis induced by AP sites.

\section{Requirement of Pold for mutagenic bypass of AP sites}

Yeast Pol $\delta$ is comprised of three subunits of 125,58 , and $55 \mathrm{kD}$, which are encoded by the POL3, POL31, and POL32 genes, respectively (Gerik et al. 1998). The 125$\mathrm{kD}$ catalytic subunit and the $58-\mathrm{kD}$ subunit are essential for viability, but the $55-\mathrm{kD}$ subunit encoded by the POL32 gene is not essential (Gerik et al. 1998). A mutation in the catalytic subunit of Pols, pol3-13, confers UV sensitivity and a deficiency in UV mutagenesis (Giot et al. 1997). The pol32s mutant is also UV-sensitive and deficient in UV mutagenesis (Gerik et al. 1998). To determine the role of Pol $\delta$ in mutagenesis induced by AP sites, we examined the effect of the pol32 $\Delta$ mutation on MMS-induced $C A N 1^{s}$ to $\operatorname{can} 1^{r}$ mutations in the apn1 apn2 $\Delta$ strain. The pol32 $\Delta$ mutant exhibits somewhat enhanced sensitivity to MMS, and MMS-induced mutations do not occur in this strain (Fig. 1; Gerik et al. 1998). For example, treatment with $0.4 \%$ MMS produced $\sim 1000$ can $1^{r}$ mutants per $10^{7}$ viable cells in the wild-type strain, whereas MMS-induced mutagenesis was abolished in the pol32s single mutant (Fig. 1B). These obser- 

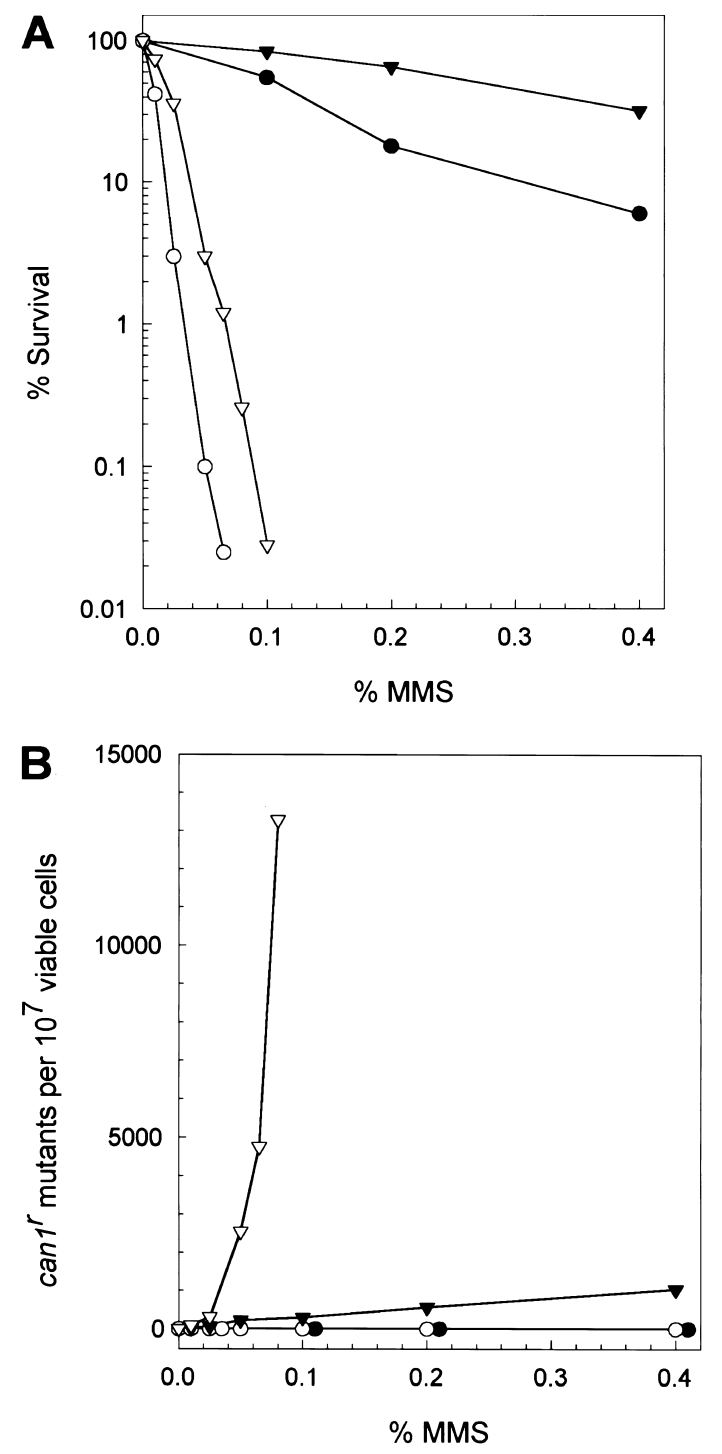

Figure 1. Effect of the pol32 $\Delta$ mutation on AP site induced mutagenesis. (A) MMS sensitivity of pol32s strains. Cells were grown overnight in YPD and treated with MMS at the indicated doses for $20 \mathrm{~min}$. Appropriate dilutions were plated on YPD. All data points represent the average of at least three experiments. (Filled inverted triangles) EMY74.7, wild type; (filled circles)

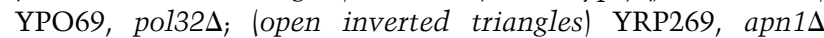

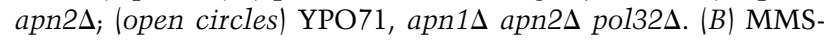
induced mutagenesis in pol32 $\Delta$ strains. Cells were grown overnight and treated with MMS at the indicated doses for $20 \mathrm{~min}$. Appropriate dilutions were plated on either YPD for viability or on synthetic medium lacking arginine but containing canavanine for measuring the frequency of $\operatorname{can} 1^{r}$ induced mutations. All data points represent of the average of at least three experiments. (Filled inverted triangles) EMY74.7, wild type; (filled circles) YPO69, pol32s; (open inverted triangles) YRP269,

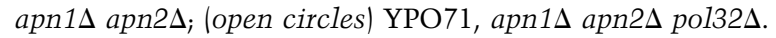

vations indicate a role for the Pol32 subunit of Pols in the mutagenic bypass of MMS-induced base damage. The apn1 1 apn2 $\Delta$ strain displays a very high incidence of MMS-induced mutations, $\sim 13,000$ per $10^{7}$ cells at $0.08 \%$
MMS, owing to the presence of unrepaired AP sites. By contrast, MMS-induced mutagenesis was abolished in the apn1s apn2s pol32s strain (Fig. 1B). The apn1s apn $2 \Delta$ pol32 $\Delta$ strain also exhibits a greater sensitivity to MMS than the apn1s apn2s strain does (Fig. 1A). These results indicate a requirement of the Pol32 subunit of Pold for the mutagenic bypass of AP sites.

\section{AP bypass by the concerted action of Pols and Polל}

AP bypass was examined with a running-start and a standing-start DNA substrate that were constructed using a linear 75-nt template DNA containing a single AP site, or, as a control, containing a $C$ residue instead of the AP site, and annealed to a $5^{\prime}-{ }^{32}$ P-labeled $29-n t$ or a $44-n t$ primer, respectively. DNA synthesis reactions with

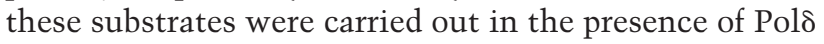
and Pol $\zeta$. We also included Rev1 in these experiments (Fig. 2). With the running-start DNA substrate, none of

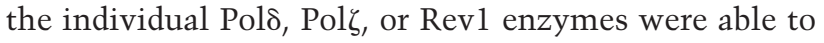
bypass the AP site (Fig. 2A, lanes 10-12). The AP site is a strong block to synthesis by $\mathrm{Pol} \zeta$, and $\mathrm{Pol} \zeta$ was unable to insert a nucleotide opposite this lesion (Fig. 2A, lane

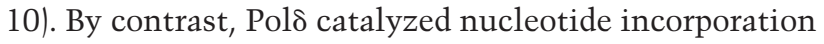
opposite the AP site but did not extend the resulting primer end (Fig. 2A, lane 11). In the control reactions, both polymerases carried out efficient synthesis to the end of the unmodified template (Fig. 2A, lanes 2,3). Efficient bypass of the AP site, however, could be achieved

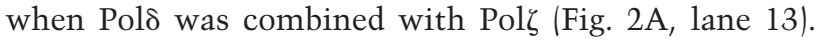
Compared to the synthesis on undamaged DNA (Fig. 2A, lane 5), Pol $\delta$ and Pol $\zeta$ together replicated through $55 \%$ of the AP sites (Fig. 2A, lane 13). In agreement with the previously published ability of Rev1 to promote AP bypass in combination with Polל (Nelson et al. 1996a), Rev 1 and Pol $\zeta$ together replicated through $32 \%$ of the AP sites (Fig. 2A, cf. lanes 6 and 14). However, Rev1 did not

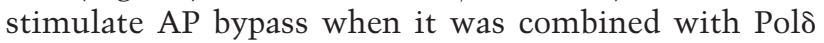
(Fig. 2A, lane 15), nor did it increase the bypass activity

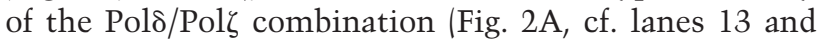
16). The key observation here is that the two DNA polymerases, Pol $\delta$ and Pol $\zeta$, together carry out efficient AP bypass, and in this reaction, Pol $\delta$ inserts the nucleotide opposite the AP site and Pol $\zeta$ then extends from that nucleotide.

With the standing-start substrate, essentially similar results were observed (Fig. 2B). Thus, the combination of Pol $\delta$ and Pol $\zeta$ bypassed the AP site about $60 \%$ as efficiently as the replication of undamaged DNA (Fig. 2B, cf. lanes 5 and 13).

\section{Nucleotide incorporated opposite the AP site by Pols}

To identify the deoxynucleotide inserted by Pols opposite the AP site, we used an 18-nt template having an AP site at position 13 from the $3^{\prime}$ end and primed with a standing-start 12-nt primer (Fig. 3). As markers we used 13-nt oligonucleotides containing the 12-nt primer with an additional $\mathrm{C}, \mathrm{A}, \mathrm{T}$, or $\mathrm{G}$ residue at position 13 ; these were distinguished by their relative electrophoretic mo- 
A

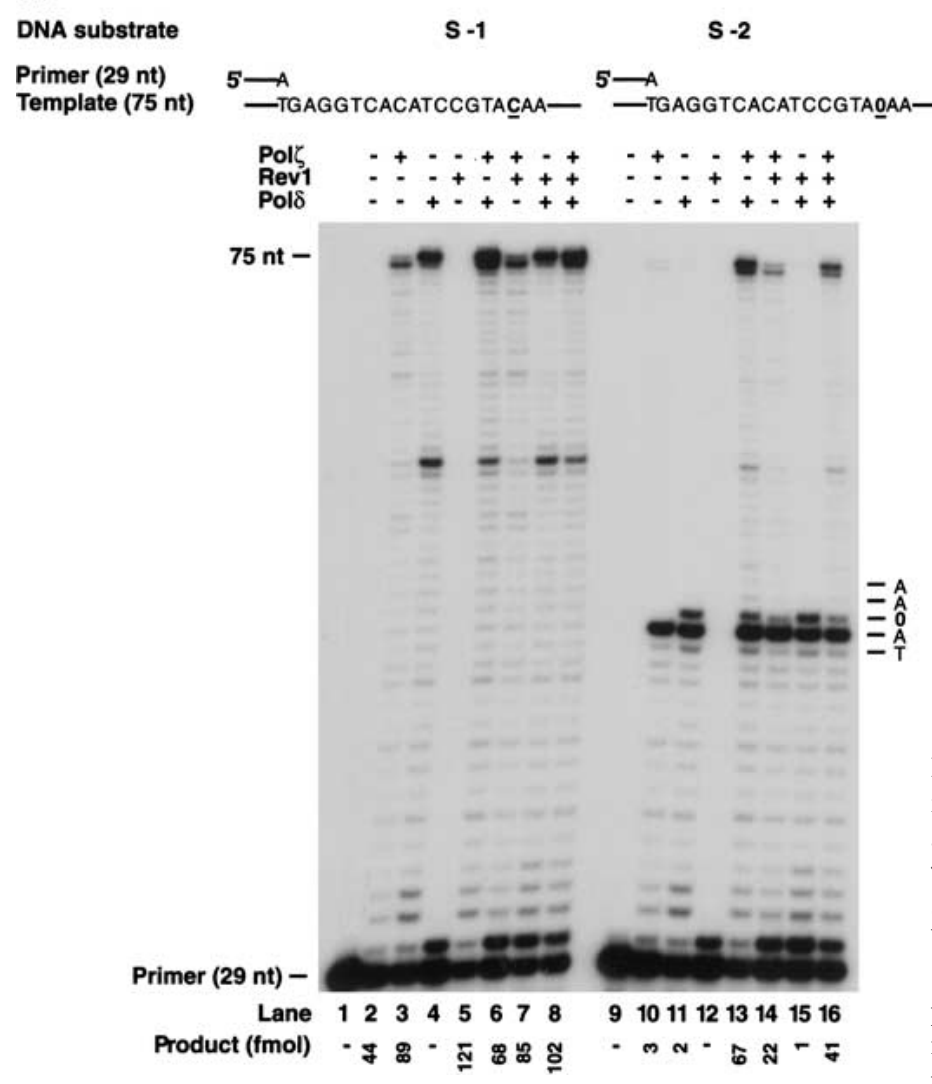

B

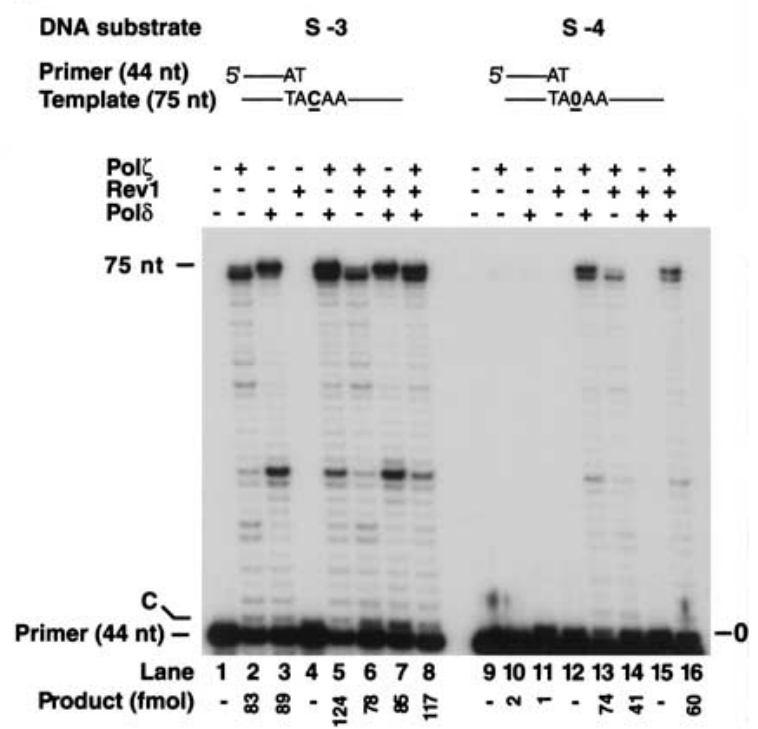

Figure 2. Translesion synthesis on DNA template containing a single AP site using Polo, Pol $\zeta$, and Rev1. Sequences adjacent to the primer-template junction are shown for the $5^{\prime}$ ${ }^{32} \mathrm{P}$-labeled primers and 75 -nt template. The position corresponding to the model abasic site on the template is indicated by $\mathbf{0}$. (A) Running-start DNA synthesis on undamaged (lanes 1-8) or single-abasic-site-containing (lanes 9-16) 75-nt template annealed with the 29 -nt primer. Polל (10 nM), Pols (10 $\mathrm{nM})$, and Rev1 (10nM) or the indicated combinations of these proteins were incubated with the DNA substrate $(20 \mathrm{nM})$ for 5 min at $30^{\circ} \mathrm{C}$ in the presence of $100 \mu \mathrm{M}$ of each of four dNTPs. The reaction products were resolved on $10 \%$ denaturing polyacrylamide gel and visualized by autoradiography. The gel was analyzed by PhosphorImager and the fraction of total radioactivity present as 46to 75 -nt products was used to calculate femtomoles of product. (B) Standing-start DNA synthesis on an undamaged (lanes 1-8) or a single-AP-site-containing (lanes 9-16) 75-nt template annealed with the 44-nt primer. The reactions and the analysis were carried out as in $A$.

bility on a $20 \%$ polyacrylamide gel (Fig. 3, lanes 9-12). We found that Polo mostly inserts an A $(-95 \%)$ and some G $(\sim 5 \%)$ opposite the AP site (Fig. 3, lane 3$)$, and Pol $\zeta$ extends from the inserted nucleotide (Fig. 3, lane 5). We also examined the ability of Rev1 and Pol $\zeta$ to insert nucleotides opposite the AP site and to extend therefrom on this template. As expected, Rev1 incorporates only a C across from the lesion (Fig. 3, lane 4), and Polל extends from this nucleotide (Fig. 3, lane 6). When Pold and Rev1 are combined, both $\mathrm{A}$ and $\mathrm{C}$ are inserted opposite the AP site, but there is no extension (Fig. 3, lane 7); extension, however, occurs upon the addition of Polל (Fig. 3, lane 8).

Steady-state kinetic analyses of nucleotide insertion opposite the AP site and of subsequent extension by $\mathrm{Pol \zeta}$

Next, we measured the kinetic parameters of nucleotide insertion opposite the AP site and of subsequent extension by Pol $\zeta$. The kinetics of insertion of a single deoxynucleotide opposite the AP site, and as a control opposite an undamaged $\mathrm{C}$ or $\mathrm{G}$ residue, and the kinetics of addition of the next correct nucleotide to various 3 '-primer termini situated across from the AP site or opposite un- damaged $\mathrm{C}$ or $\mathrm{G}$ residues were determined as a function of deoxynucleotide concentration under steady-state conditions. The patterns of insertion of nucleotides opposite the AP site and of extension from the $G, A, T$, or C 3'-primer termini situated across from the AP site are shown in Figure 4. From the kinetics of deoxynucleotide incorporation, the apparent $K_{\mathrm{m}}$ and $V_{\max }$ values were determined, and the frequency of deoxynucleotide insertion $\left(f_{\text {inc }}\right)$ and extension $\left(f_{\text {ext }}^{0}\right)$ were calculated (Mendelman et al. 1990; Goodman et al. 1993; Creighton et al. 1995). As shown in Table 2, Pol $\zeta$ misincorporates nucleotides opposite a template $\mathrm{C}$ or $\mathrm{G}$ with a frequency of $\sim 10^{-4}$, and it inserts nucleotides opposite the AP site with a frequency of $10^{-4}$ to $10^{-5}$. However, Pol $\zeta$ extends from the primer end situated opposite the abasic site very efficiently. Compared to the extension from a $G$ opposite $\mathrm{C}$ in the template, Pol $\zeta$ extended from an $\mathrm{A}$, a $\mathrm{G}$, a $\mathrm{C}$, and a $\mathrm{T}$ residue opposite the AP site with frequencies of $\sim 3 \times 10^{-1}, 1 \times 10^{-1}, 2 \times 10^{-2}$, and $7 \times 10^{-3}$, respectively (Table 3 ). Thus, Pol $\zeta$ extends from an A or a $\mathrm{G}$ opposite the AP site about 3- and 10-fold less efficiently than it extends from a $\mathrm{G}$ opposite template $\mathrm{C}$, whereas $\mathrm{C}$ opposite the AP site is extended about 50 -fold less efficiently than is G opposite C. Polל also extends 


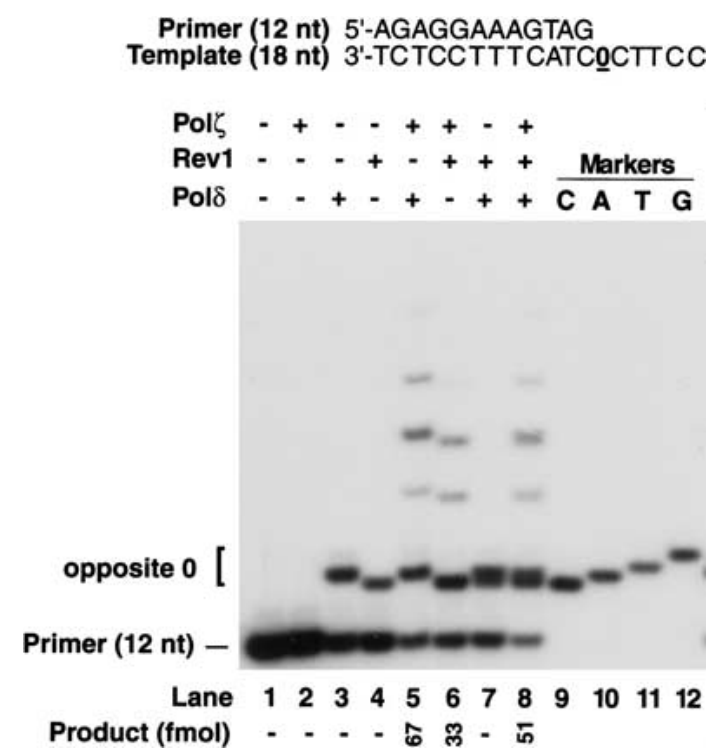

Figure 3. Nucleotide incorporation opposite AP site and extension from the ensuing primer end. Nucleotide incorporation opposite an AP site in reactions catalyzed by different combi-

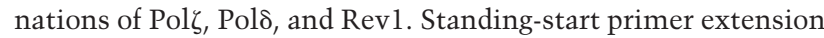
reactions were carried out on an AP-site-containing 18-nt template primed with the $5^{\prime}-{ }^{32} \mathrm{P}$-labeled 12 -nt oligonucleotide. The position of the AP site on the template is indicated by $\mathbf{0}$. The

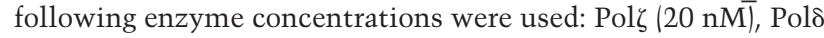
(20 nM), and Rev1 (20 nM). Electrophoretic mobilities of reaction products were compared with those of 13-nt oligonucleotide standards containing a C (lane 9), an A (lane 10), a T (lane 11), or a G (lane 12) residue opposite the AP site at position 13.

from 3 '-terminal mispaired ends quite readily. For example, an A opposite template $\mathrm{C}$ is extended about $25 \%$ as efficiently as a G opposite template C. Overall, Pol $\zeta$ extends from base mispairs with frequencies of $10^{-1}$ to $10^{-2}$ (Table 3).

Polל extension of primer end situated opposite the AP site

Next, we examined the ability of Pol $\zeta$ to extend from various $3^{\prime}$ termini situated across from the AP site in the 18-nt template in the presence of $100 \mu \mathrm{M}$ of each of the four dNTPs (Fig. 5). Although Pol $\zeta$ extended each of the C, A, T, or G 3'-primer ends situated opposite the AP site (Fig. 5, lanes 2-5), extension from A was $\sim 5$-fold more efficient than from the $\mathrm{C}$ primer end, and the order and the frequency of extension from various 3 '-terminal deoxynucleotides were A: G: C: T=9.8:6.7:1.7:1. Thus, even under saturating dNTP concentrations, Pol $\zeta$ shows a preference for extending from an A opposite the AP site.

\section{Discussion}

To determine the mutational specificity of AP sites in eukaryotes, we analyzed the sequence of $\operatorname{can}^{r}$ mutations obtained following MMS treatment of the apn1s apn2s yeast strain. Our results indicate that A is inserted most frequently opposite the AP site, and that $\mathrm{C}$, $\mathrm{G}$, and $\mathrm{T}$ together are inserted at about $50 \%$ the frequency of A. Previously, in one study done in yeast with plasmids containing an AP site, C was found to be inserted preferentially ( $80 \%)$ opposite this lesion (Gibbs and Lawrence 1995), whereas in another study with the SUP4 gene carried on a plasmid, the frequency of spontaneous $\mathrm{A} \cdot \mathrm{T} \rightarrow \mathrm{C} \cdot \mathrm{G}$ events increased in the apn1s strain (Kunz et al. 1994), suggesting an insertion of G opposite the AP site resulting from the loss of an A. Thus, the mutagenic consequences of AP sites in yeast may differ depending on whether the lesion is on a plasmid or in the genome. Also, we note that mutagenesis at the SUP4 locus differs from mutagenesis at the majority of loci (Drake 1991).

NMR structural studies have shown that A fits into the double helix opposite the AP site without conferring any distortion. Such DNA retains all aspects of B-form DNA, in which the A residue and the abasic residue lie inside the double helix, and the melting temperature of the A A AP site is the same as that of the A - T base pair (Cuniasse et al. 1987, 1990; Kalnik et al. 1988). Thus, the geometry of the A residue opposite the AP site is very similar to that of the A . T base pair. G opposite the AP site is less stable, but at low temperatures this residue is also predominantly intrahelical (Cuniasse et al. 1990). By contrast, a pyrimidine opposite the AP site is not stable, and in this case, both the pyrimidine and the abasic sugar are extrahelical (Cuniasse et al. 1990). In Escherichia coli, synthesis past an AP site is accompanied by the preferential incorporation of an A opposite this lesion, a phenomenon known as the "A-rule" (Strauss 1991). Polס may act in a similar fashion, as it predominantly inserts an A opposite the AP site. Although the geometry of an

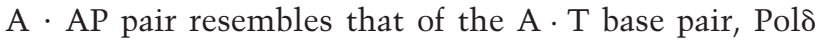
nonetheless can distinguish between these pairs, since it does not extend from the A residue of an A - AP pair.

Genetic studies in yeast have indicated the absolute requirement of Pol $\zeta$ for mutagenesis induced by AP sites (Johnson et al. 1998). However, on its own, Polל bypasses this lesion very poorly. This is because Pol $\zeta$ is highly inefficient in inserting deoxynucleotides opposite the AP site, but it efficiently extends from the nucleotide inserted opposite the AP site by another DNA polymerase. Steady-state kinetic analyses further demonstrate that Pol $\zeta$ extends most efficiently from an A opposite the AP site. Relative to the extension from G opposite template $\mathrm{C}$, Pol $\zeta$ extends from an A opposite the AP site with a frequency of $3 \times 10^{-1}$, and it extends from a G opposite this lesion with a frequency of $\sim 10^{-1}$. Thus, the insertion of an A opposite the AP site by Polo, followed by the efficient extension of this primer end by Pol $\zeta$, explains our in vivo mutagenesis results of the preferential incorporation of an A opposite this DNA lesion.

In addition to the insertion of an $\mathrm{A}$, we also observe the insertion of $C, G$, and $T$ residues opposite the AP site. Although our studies on mutational inactivation of Rev1 C-transferase activity have provided no evidence for the requirement of this activity in the mutagenic 
A

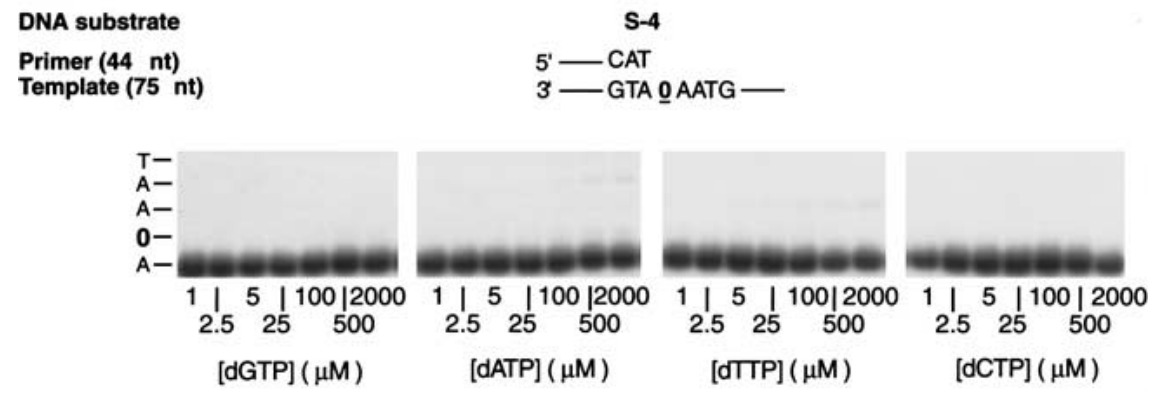

B

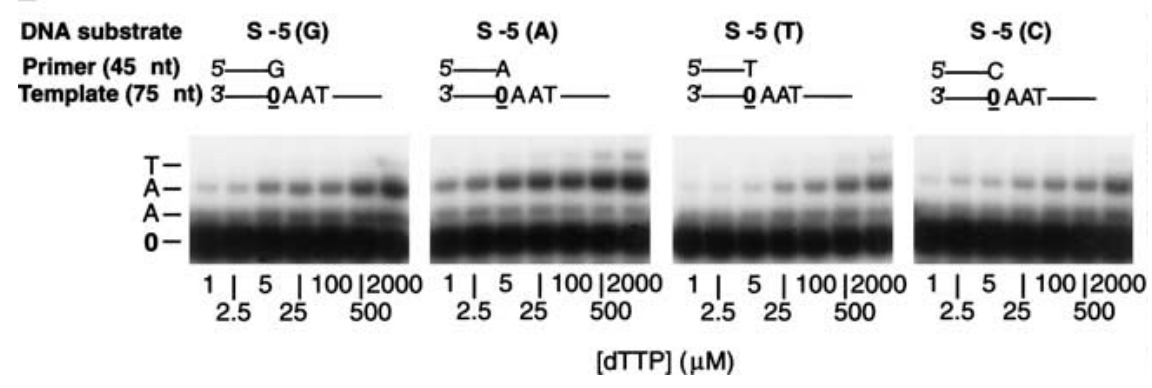

Figure 4. Steady-state deoxynucleotide incorporation and primer-extension reactions catalyzed by Pol $\zeta$ on an AP-site-containing DNA template. (A) Deoxynucleotide incorporation opposite a template AP site. Pol $\zeta(5 \mathrm{nM})$ was incubated for $1 \mathrm{~min}$ at $30^{\circ} \mathrm{C}$ with the S-4 primer-template DNA substrate $(20 \mathrm{nM})$ and increasing concentrations $(0-2000 \mu \mathrm{M})$ of a single deoxynucleotide (dGTP, dATP, dTTP, or $\mathrm{dCTP}$ ) in the standard reaction buffer. The quenched samples were analyzed by $10 \%$ denaturing polyacrylamide gel electrophoresis. $(B)$ Extension of primers containing a $\mathrm{G}$, an $\mathrm{A}$, a $\mathrm{T}$, or a $\mathrm{C}$ residue opposite the AP site by Pol $\zeta$. Primers differing only in the last nucleotide at the $3^{\prime}$ end were annealed separately to an AP-site-containing DNA template as shown on the top. Reactions were carried out in the presence of increasing dTTP concentration $10-2000$ $\mu \mathrm{M})$ as in $A$. The position of the AP site in the template is indicated by 0 . bypass of AP sites, they do not rule out a minor contribution of this activity to AP bypass. Since only $~ 10 \%$ of $\operatorname{can} 1^{r}$ mutations are expected to derive from the insertion of C opposite the AP site, it would be difficult to ascertain such a limited involvement of Rev1 C-transferase activity in AP bypass from the analyses of mutation frequencies. Furthermore, there is the possibility that enzymes other than Rev1 also insert a C opposite the AP site. Thus, although the Revl protein is essential for mutagenesis induced by AP sites, its C-transferase activity is not prominently involved in the bypass of this lesion. Presumably, the indispensability of the Rev1 protein for AP mutagenesis derives from its structural role during Pol $\zeta$-dependent bypass of this lesion (see Fig. 6). Since Polo would be the first polymerase to arrive at the
AP site, we surmise that its ability to insert an A opposite this lesion supercedes the insertion of C by Rev1, and also, since Pol $\zeta$ extends from an A opposite the AP site about 15 -fold more efficiently than from C (Table 3), we expect $A$ to be incorporated much more frequently during AP bypass than is C. Unlike the efficient bypass of a cis-syn T-T dimer (Johnson et al. 2000b; Washington et al. 2000), or an 8-oxoguanine lesion (Haracska et

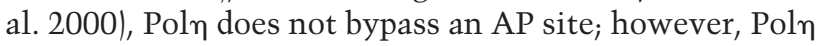
may contribute to the insertion of a G opposite the AP site (Haracska et al. 2001). In humans, Polı, a very low fidelity enzyme, would additionally function in the insertion of nucleotides opposite the AP sites (Johnson et al. 2000a). Therefore, AP bypass in eukaryotes is mediated by the sequential action of two DNA polymerases,

Table 2. Kinetic parameters of nucleotide insertion reactions catalyzed by yPolל

\begin{tabular}{|c|c|c|c|c|c|}
\hline Site & $\begin{array}{l}\text { dNTP } \\
\text { added }\end{array}$ & $\begin{array}{c}\mathrm{K}_{\mathrm{m}} \\
(\mu \mathrm{M})\end{array}$ & $\begin{array}{c}\mathrm{V}_{\max } \\
(\% / \min )\end{array}$ & $\mathrm{V}_{\max } / \mathrm{K}_{\mathrm{m}}$ & $\mathrm{f}_{\text {inc }}$ \\
\hline \multicolumn{6}{|c|}{ Insertion opposite abasic site } \\
\hline & dGTP & $543 \pm 42$ & $1.4 \pm 0.19$ & 0.003 & $2.1 \times 10^{-5}$ \\
\hline $5^{\prime}----\mathrm{CAT}$ & dATP & $81 \pm 2.9$ & $4.8 \pm 0.07$ & 0.059 & $4.2 \times 10^{-4}$ \\
\hline \multirow[t]{2}{*}{----GTA $\underline{0}$ AA-- } & dTTP & $125 \pm 8.5$ & $3.3 \pm 0.09$ & 0.026 & $1.8 \times 10^{-4}$ \\
\hline & $\mathrm{dCTP}$ & $113 \pm 14$ & $1.4 \pm 0.12$ & 0.012 & $8.6 \times 10^{-5}$ \\
\hline \multicolumn{6}{|c|}{ Insertion opposite $\mathrm{C}$} \\
\hline & dGTP & $0.11 \pm 0.008$ & $15.4 \pm 2.0$ & 140 & 1 \\
\hline $5^{\prime}----\mathrm{CAT}$ & dATP & $267 \pm 18$ & $2.1 \pm 0.14$ & 0.0078 & $5.5 \times 10^{-5}$ \\
\hline \multirow[t]{2}{*}{----GTAC AA-- } & dTTP & $552 \pm 96$ & $3.8 \pm 1.1$ & 0.0069 & $4.9 \times 10^{-5}$ \\
\hline & dCTP & $321 \pm 14$ & $2.9 \pm 0.32$ & 0.009 & $6.4 \times 10^{-5}$ \\
\hline \multicolumn{6}{|c|}{ Insertion opposite $G$} \\
\hline & dGTP & $344 \pm 24$ & $4.3 \pm 0.12$ & 0.0125 & $1 \times 10^{-4}$ \\
\hline 5'----CAT & dATP & $118 \pm 5$ & $1.4 \pm 0.33$ & 0.012 & $1 \times 10^{-4}$ \\
\hline \multirow[t]{2}{*}{----GTAG AA-- } & dTTP & $428 \pm 54$ & $3.6 \pm 0.28$ & 0.0084 & $7 \times 10^{-5}$ \\
\hline & dCTP & $0.14 \pm 0.03$ & $16.7 \pm 1.1$ & 119.3 & 1 \\
\hline
\end{tabular}


Table 3. Kinetic parameters of extension reactions catalyzed by yPolל

\begin{tabular}{|c|c|c|c|c|c|}
\hline Site & $\begin{array}{l}\text { dNTP } \\
\text { added }\end{array}$ & $\begin{array}{l}\mathrm{K}_{\mathrm{m}} \\
(\mu \mathrm{M})\end{array}$ & $\begin{array}{c}\mathrm{V}_{\max } \\
(\% / \min )\end{array}$ & $\mathrm{V}_{\max } / \mathrm{K}_{\mathrm{m}}$ & $\mathrm{f}_{\text {ext }}^{0}$ \\
\hline \multicolumn{6}{|c|}{ Extension from G, A, T, or C opposite abasic site } \\
\hline $\begin{array}{l}\text { 5' ----CATG } \\
\text {---GTA } \underline{0} \text { AA-- }\end{array}$ & dTTP & $6.5 \pm 0.55$ & $12 \pm 2.2$ & 1.85 & $9.5 \times 10^{-2}$ \\
\hline $\begin{array}{l}5^{\prime} \text {----CATĀ } \\
\text {---GTA } \underline{0} \text { AA-- }\end{array}$ & dTTP & $2.3 \pm 0.17$ & $13 \pm 1.5$ & 5.65 & $2.9 \times 10^{-1}$ \\
\hline $\begin{array}{l}5^{\prime} \text {----CATT̄ } \\
\text {---GTA } \underline{0} \text { AA-- }\end{array}$ & dTTP & $49 \pm 3.7$ & $6.8 \pm 0.24$ & 0.14 & $7.2 \times 10^{-3}$ \\
\hline $\begin{array}{l}5^{\prime} \text {----CATC } \\
\text {---GTA므 AA-- }\end{array}$ & dTTP & $21 \pm 1.2$ & $8.4 \pm 1.3$ & 0.4 & $2.1 \times 10^{-2}$ \\
\hline \multicolumn{6}{|c|}{ Extension from $\mathrm{G}, \mathrm{A}, \mathrm{T}$ or $\mathrm{C}$ opposite $\mathrm{C}$} \\
\hline $\begin{array}{l}\text { 5'---CATG } \\
\text {----GTAC AA-- }\end{array}$ & dTTP & $0.35 \pm 0.02$ & $6.8 \pm 0.56$ & 19.4 & 1 \\
\hline $\begin{array}{l}5^{\prime}---- \text { CATA } \\
--- \text { GTAC AA-- }\end{array}$ & dTTP & $2.3 \pm 0.22$ & $12 \pm 0.89$ & 5.22 & $2.6 \times 10^{-1}$ \\
\hline $\begin{array}{l}5^{\prime} \text {----CATT } \\
\text {---GTAC AA-- }\end{array}$ & dTTP & $15 \pm 0.9$ & $8.9 \pm 1.3$ & 0.59 & $3.0 \times 10^{-2}$ \\
\hline $\begin{array}{l}5^{\prime} \text {----CATC } \\
\text {----GTAC AA-- }\end{array}$ & dTTP & $26 \pm 2.8$ & $3.9 \pm 0.08$ & 0.15 & $7.7 \times 10^{-3}$ \\
\hline \multicolumn{6}{|c|}{ Extension from $G, A, T$ or $C$ opposite $G$} \\
\hline $\begin{array}{l}\text { 5' ----CATG } \\
\text {----GTAG AA-- }\end{array}$ & dTTP & $6.9 \pm 0.2$ & $10.7 \pm 1.8$ & 1.55 & $3.6 \times 10^{-2}$ \\
\hline $\begin{array}{l}5^{\prime}--- \text { CATA } \\
---- \text { GTAG AA-- }\end{array}$ & dTTP & $2.1 \pm 0.14$ & $8.4 \pm 0.77$ & 4.0 & $9.3 \times 10^{-2}$ \\
\hline $\begin{array}{l}5^{\prime} \text {----CATT } \\
\text {---GTAG AA-- }\end{array}$ & dTTP & $28.8 \pm 4.6$ & $14.1 \pm 1.7$ & 0.48 & $1.1 \times 10^{-2}$ \\
\hline $\begin{array}{l}5^{\prime} \text {----CATC } \\
\text {----GTAG AA-- }\end{array}$ & dTTP & $0.23 \pm 0.018$ & $9.9 \pm 1.6$ & 43 & 1 \\
\hline
\end{tabular}

wherein the extension step depends solely on Pol $\zeta$, but the insertion step can be quite varied, involving not only the predominant action of the replicative DNA polymerase, Pold, but also the less prominent role of various translesion synthesis polymerases.

The absolute requirement of Pol $\zeta$ for the extension step explains its indispensability for AP mutagenesis.

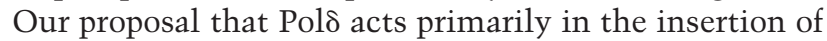
an A, whereas Rev1 and the other translesion synthesis enzymes catalyze the insertion of $\mathrm{C}$ and of other nucleotides opposite the AP site, however, fails to explain the absolute requirement of the Pol32 subunit of Pols and of Rev1 in AP mutagenesis. It is possible that the requirement of Pol32 reflects the need for this Pols subunit in the assembly of Pol $\zeta$ and Rev1 at the lesion site (Fig. 6B). Because Pol $\delta$ is involved in the replication of both the leading and lagging DNA strands and binds the two strands as a dimer, following the incorporation of a nucleotide opposite the AP site, Polo may be displaced from the damage-containing template upon ubiquitin conjugation by the Rad6-Rad18 complex (Bailly et al. 1997), which is essential for damage bypass (Fig. 6A). If, however, Pols is unable to insert a nucleotide opposite the AP site, or if the inserted nucleotide is removed by its proofreading exonuclease activity, then Rad6-Rad18mediated displacement of Polo may occur before the insertion step, whereupon any of the translesion synthesis enzymes such as Rev1, Poln, and additionally, Polı in

\section{Primer (13 nt) 5'-AGAGGAAAGTAGN Template (18 nt) 3'-TCTCCTTTCATCOCTTCC}

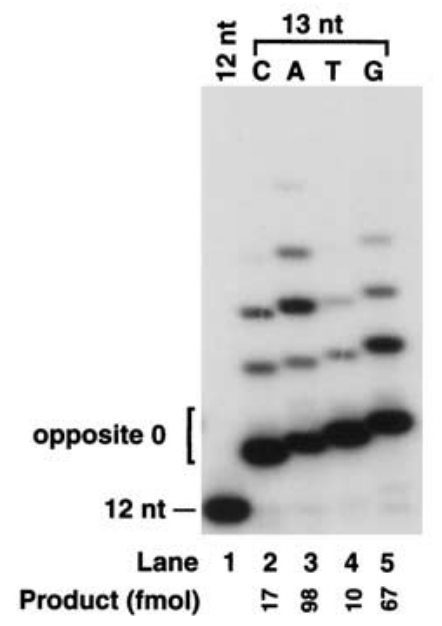

Figure 5. Extension of primers with various 3 '-terminal primer dNMPs opposite the template AP site by Pol $\zeta$. Four different $5^{\prime}{ }^{32} \mathrm{P}$-labeled 13 -nt primers, differing only in their $3^{\prime}$-terminal nucleotide, were annealed to an 18-nt template containing an AP site. In the template-primer shown, $\mathrm{N}$ designates the position of the variable terminal primer dNMP and $\mathbf{0}$ designates the position of the AP site. Lane 1 has a 12-nt primer and lacks the 13 th nucleotide indicated by N. DNA substrate $(20 \mathrm{nM})$ was assayed with $20 \mathrm{nM}$ Pol $\zeta$ (lanes 1-5) in the presence of each of the four dNTPs $(100 \mu \mathrm{M})$. 
Haracska et al.

A

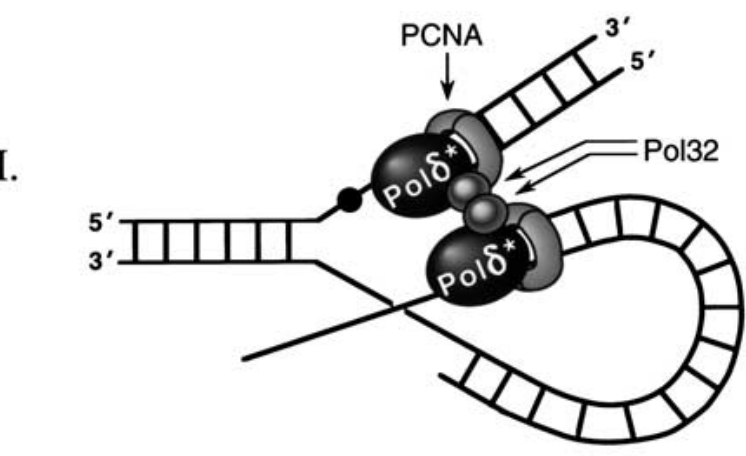

Insertion of
"A" by Pol $\delta$

II.

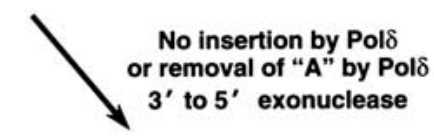

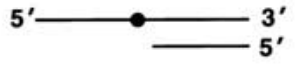

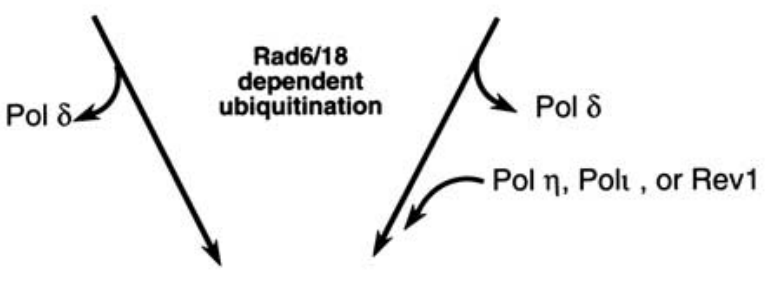

III.

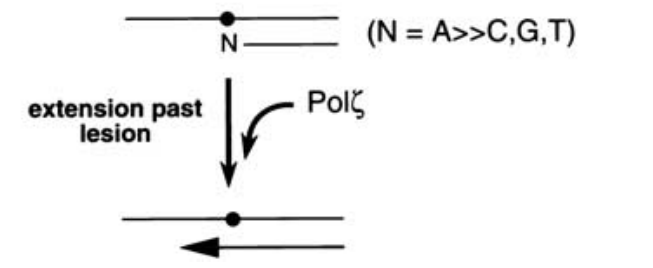

B

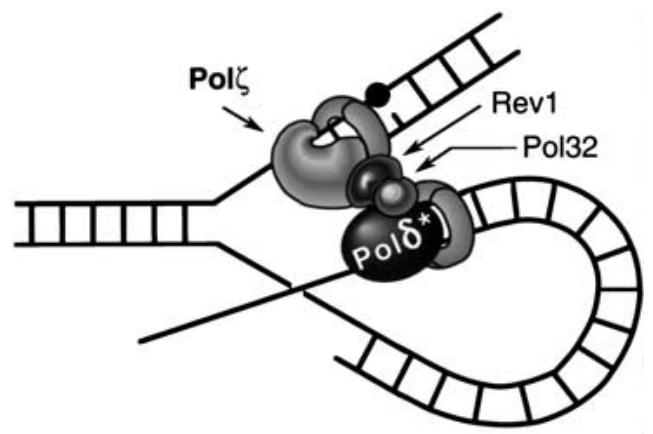

Figure 6. Mechanisms of AP bypass. (A) The insertion and extension steps of AP bypass. (I) Pol ${ }^{\star}$ represents the Pol3-Pol31 heterodimer, and the Pol32 subunit of

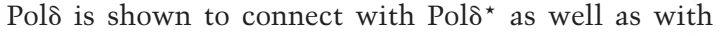
PCNA (Burgers and Gerik 1998). An abasic site (filled circle) is present on the leading strand. (II) Following the insertion of an A or before it, the Rad6-Rad18-mediated ubiquitination leads to the displacement of Polo stalled at the lesion site. In the absence of an A insertion (or,

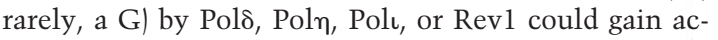
cess to the lesion site and insert a nucleotide opposite the AP site. (III) Polל extends from the nucleotide inserted opposite the AP site by Pold or by one of the translesion synthesis DNA polymerases. $(B)$ Roles of Pol32 and Rev1 in the mutagenic bypass of AP sites. The essential structural role of Rev1 in mutagenic by-

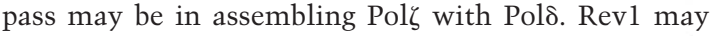
interact with Pol32, and also with PCNA/RFC, and

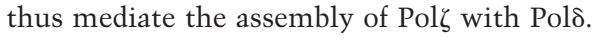

humans, may gain access to the lesion site and insert a nucleotide opposite the AP site (Fig. 6A). Following the insertion of a nucleotide by Pold or by one of the translesion synthesis polymerases, Pol $\zeta$ may be targeted to the lesion site via its interaction with Rev1, which in turn may bind the Pol32 subunit of Pols remaining bound to the undamaged DNA strand (Fig. 6B). The nonenzymatic requirement of Rev1 may therefore reflect the need for this protein in the assembly of Pol $\zeta$ with Pol $\delta$ via its Pol32 subunit. Rev1 may also facilitate interactions of Pol $\zeta$ with the other components of the replication machinery such as PCNA and RFC (Fig. 6B). Accordingly, the requirement of Pol32 as well as Rev1 for AP bypass may derive from their respective roles in providing access of Pol $\zeta$ to the lesion site.

The insertion of an A by Pols opposite the AP site raises the possibility that Pol $\delta$ is an A-rule polymerase, able to insert an A opposite various other DNA lesions as well (Strauss 1991). For example, in addition to the formation of cyclobutane dimers at TT sequences, UV induces lesions at the $5^{\prime}-\mathrm{TC}-3^{\prime}$ and $5^{\prime}$-CC-3' sequences. The $3^{\prime}-\mathrm{C}$ in both sequences is highly mutagenic, and in both yeast and humans, UV-induced mutations occur predominantly by a $3^{\prime}-\mathrm{C} \rightarrow \mathrm{T}$ transition that results from the insertion of an A opposite the $3^{\prime}$ damaged $\mathrm{C}$ during DNA replication (Armstrong and Kunz 1990; Brash 1997; Canella and Seidman 2000). Genetic studies in yeast have shown that Polל is responsible for the $3^{\prime}$ $\mathrm{C} \rightarrow \mathrm{T}$ mutagenesis resulting from the replicative bypass of UV lesions at TC and CC sites (Yu et al. 2001). However, because Polל functions at the step of extending from the nucleotide incorporated opposite the 3 ' residue of UV lesions by another DNA polymerase (Johnson et al. 2000a), we suggest that Pold is the enzyme responsible for inserting an A opposite the $3^{\prime}$-C of UV lesions formed at TC and CC sites. Hence, by inserting an A

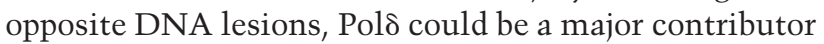
to DNA damage-induced mutagenesis in eukaryotes.

\section{Materials and methods}

\section{Generation of yeast null mutations}

The strains used in the genetic studies were EMY74.7 (MAT $\alpha$ his3s-100, leu2-3, 112, $\operatorname{trp} 1 \Delta$, ura3-52) and its derivatives. To construct the pol32 $\Delta$-generating plasmid, the 1.2- and 1-kb PCR products corresponding to the 5 '- and 3 '-flanking regions of the POL32 gene, respectively, were directionally cloned into pUC19. The URA3 geneblaster fragment containing the yeast $U R A 3$ gene flanked by the duplicated Salmonella typhimurium his $G$ gene (Alani et al. 1987) was then inserted between the two 
PCR products. The resulting pol32A-generating plasmid was digested with $P v u I I$, which releases a 6-kb fragment, introduction of which into yeast deletes nucleotides from +6 to +960 of the 1053-nt POL32 open reading frame. The presence of the pol32 mutation in the various yeast strains was confirmed by PCR of genomic DNA. Loss of the URA3 gene was selected for by plating strains on medium containing 5 -fluoro-orotic acid.

\section{Construction of the Rev1 C-transferase mutant}

A 5.6-kb DNA fragment containing the entire yeast REV1 gene and including $\sim 1.1 \mathrm{~kb}$ of $5^{\prime}$-flanking DNA sequence and $1.4 \mathrm{~kb}$ of 3'-flanking DNA sequence, respectively, was cloned into pUC19, generating plasmid pBJ67, which was used as the starting material for constructing the Rev1 C-transferase mutant. This mutant, in which D467 and E468 are each changed to A, was generated by mutagenic PCR using the antisense oligonucleotide N4865 (5'-CACAAACAGCTGCAGCAATAGATA TAGGTAAAATC-3') and the sense oligonucleotide N4866 (5' TCTATTGCTGCAGCTGTTTGTGTGAGGATAATCCC-3'), resulting in a PCR fragment containing the D467, E468 $\rightarrow$ A467, A468 mutation as well as a PstI site at these positions. A 250-bp BamHI-PstI PCR fragment encompassing nucleotides +1158 to +1401 of the REV1 gene, and a 1560-bp PstI-Asp 718 PCR fragment encompassing nucleotides +1401 to the termination codon at position +2958 , were directionally cloned into the BamHI-Asp 718 sites of pUC19, generating plasmid pBJ652. The presence of the A467, A468 mutation located at the PstI site was confirmed by DNA sequencing. Subsequently, the remainder of the REV1 ORF, from nucleotides +1 to +1158 along with the 5 '-flanking DNA and 3 '-flanking DNA, obtained from pBJ67 was cloned into pBJ652, regenerating the entire 5.6-kb REV1 DNA fragment, but now containing the rev1 D467, E468 $\rightarrow$ A467, A468 mutation. The wild-type and mutant genes were then cloned into YCplac33, a low-copy-number vector that carries the yeast URA3 gene as a selectable marker, as 5.4-kb SphI-BgIII fragments, generating plasmids pBJ660 and pBJ661, respectively.

\section{MMS sensitivity and MMS-induced mutagenesis}

Cells were grown overnight in YPD medium, sonicated to disperse clumps, washed, and resuspended in $0.05 \mathrm{M} \mathrm{KPO}_{4}$ buffer at $\mathrm{pH}$ 7.0. Appropriate dilutions of MMS were added to $1-\mathrm{mL}$ suspensions of cells adjusted to $1.5 \times 10^{8}$ cells $/ \mathrm{mL}$. Samples were incubated with vigorous shaking for $20 \mathrm{~min}$ at $30^{\circ} \mathrm{C}$. Reactions were terminated by the addition of $1 \mathrm{~mL}$ of $10 \%$ sodium-thiosulfate. Appropiate dilutions were plated on YPD for viability determinations, and on synthetic complete medium lacking arginine but containing canavanine for determining the frequency of $\operatorname{can} 1^{r}$ mutations. Plates were incubated at $30^{\circ} \mathrm{C}$, and colonies were counted after $3 \mathrm{~d}$ for viability and after $4-5 \mathrm{~d}$ for mutagenesis.

For determining the mutational specificity of AP sites, the apn $1 \Delta$ apn $2 \Delta$ strain was treated with $0.08 \%$ MMS for 20 min at $30^{\circ} \mathrm{C}$. Genomic DNA was isolated from $\operatorname{can} 1^{r}$ mutants resulting from AP bypass and sequenced. Under these experimental conditions, relative to the spontaneous $\operatorname{can} 1^{r}$ mutation frequency, the increase in MMS-induced $\operatorname{can}^{r}$ mutations in the apn1s apn2s strain was $>100$-fold.

\section{Purification of enzymes}

Yeast Polס was purified as described (Burgers and Gerik 1998). The purification of yeast Pol $\zeta$ and Revl was based on methods published previously, but in both cases the purification procedure included one additional chromatographic step. A GST-
Rev3 fusion protein in complex with Rev7 protein (Polל) was overexpressed in yeast strain Sc334 containing the plasmids pGST-REV3 and pREV7. The purification of GST-Rev3-Rev7 on glutathione-Sepharose 4B chromatography was carried out as described (Nelson et al. 1996b). Proteins eluted with glutathione from the matrix were dialyzed against buffer A $\left(25 \mathrm{mM} \mathrm{NaPO}_{4}\right.$ at $\mathrm{pH} 7.4,100 \mathrm{mM} \mathrm{NaCl}, 10 \%$ glycerol, $0.01 \% \mathrm{NP}-40,5 \mathrm{mM}$ DTT, $0.5 \mathrm{mM}$ EDTA), followed by loading onto a Mini-Q column (Pharmacia). The column was washed with 20 column volumes of buffer $\mathrm{A}$, and the proteins were eluted with a gradient of 10 column volumes of $100-500 \mathrm{mM} \mathrm{NaCl}$. The GSTRev3-Rev7 peak fractions were pooled and concentrated by dialysis in buffer A containing $200 \mathrm{mM} \mathrm{NaCl}$ and $50 \%$ glycerol. To overexpress Rev1 protein as a GST fusion protein, plasmid pBJ 392 (PKG : GST-REV1) was introduced in yeast strain LY2 (Mata gal1 reg1-501 leu2-3,-112 ura3-52 trp1s pep4-3 prb1-112). Cells were grown for $12 \mathrm{~h}$ in synthetic complete medium lacking leucine. Purification of GST-Rev1 on glutathione-Sepharose 4B was carried out as described for GST-Rev3-Rev7. The eluted protein sample was dialyzed against buffer A, followed by MiniS (Pharmacia) chromatography. GST-Rev1 protein was eluted by $100-500 \mathrm{mM} \mathrm{NaCl}$ gradient in buffer $\mathrm{A}$, and pooled fractions were frozen in aliquots under liquid nitrogen and kept at $-70^{\circ} \mathrm{C}$.

\section{DNA synthesis reactions}

Standard DNA polymerase reactions $(10 \mu \mathrm{L})$ contained $40 \mathrm{mM}$ Tris- $\mathrm{HCl}$ at $\mathrm{pH} 7.5,5 \mathrm{mM} \mathrm{MgCl} 2,1 \mathrm{mM}$ dithiothreitol, bovine serum albumin $(100 \mu \mathrm{g} / \mathrm{mL}), 10 \%$ glycerol, $100 \mu \mathrm{M}$ dNTP, and 20 nM 5'- ${ }^{32}$ P-labeled oligonucleotide primer annealed to an oligonucleotide template. Reactions were initiated by adding the enzymes Pol $\zeta$, Pol $\delta$, or Rev1 in the amounts indicated in the figure legends. After incubation for $5 \mathrm{~min}$ at $30^{\circ} \mathrm{C}$, reactions were terminated by the addition of $40 \mu \mathrm{L}$ of loading buffer containing $20 \mathrm{mM}$ EDTA, $95 \%$ formamide, $0.3 \%$ bromphenol blue, and $0.3 \%$ cyanol blue. The reaction products were subjected to electrophoresis in $10 \%$ or $20 \%$ polyacrylamide gels containing $8 \mathrm{M}$ urea and visualized autoradiographically. Quantitation of reaction products was done with a Molecular Dynamics STORM phosphoimager and the ImageQuant software. DNA substrates S-2, S-4, S-5(G), S-5(A), S-5(T), S-5(C) were generated by annealing the 75-nt oligonucleotide template $5^{\prime}$-AGCTACC ATGCCTGCCTCAAGAGTTCGTAAATGCCTACACTGGA GTACCGGAGCATCGTCGTGACTGGGAAAAC-3', which contained a model abasic site (a tetrahydrofuran moiety, purchased from Midland Co.) at the underlined position, to the 29-nt, 44-nt, and four different 45-nt $5^{\prime}$ - $^{32}$ P-labeled oligonucleotide primers, N4577: 5'-GTTTTCCCAGTCACGACGATGCT CCGGTA-3', N4309: 5'-GTTTTCCCAGTCACGACGATGCT CCGGTACTCCAGTGTAGGCAT-3', or oligonucleotides that contain N4309 with one additional G,A,T, or C residue at its 3' end, respectively. In the control nondamaged substrate $\mathrm{S}-1$ or S-3, the 75-nt template oligonucleotide with a C residue instead of the AP site at position 45 was annealed to N4577 and N4309, respectively. The sequences of DNA substrates containing 18nt template oligonucleotides annealed to 12-nt primer DNA are shown in the figures.

\section{Steady-state kinetic analyses}

Analysis of kinetic parameters for deoxynucleotide incorporation opposite the AP site or primer extension from nucleotides opposite this lesion was done as described (Mendelman et al. 1990; Goodman et al. 1993; Creighton et al. 1995). Briefly, Polל was incubated with increasing concentrations of a single deoxynucleotide $(0-2000 \mu \mathrm{M})$ for 1 min under standard reaction conditions. Gel band intensities of the substrates and products were 
quantitated by PhosphorImager. The percentage of primer extended was plotted as a function of dNTP concentration, and the data were fit by nonlinear regression using SigmaPlot 5.0 to the Michaelis-Menten equation describing a hyperbola, $V=\left(V_{\max } \times[\mathrm{dNTP}] /\left(K_{\mathrm{m}}+[\mathrm{dNTP}]\right)\right.$. Apparent $K_{\mathrm{m}}$ and $V_{\max }$ steady-state parameters were obtained from the fit and used to calculate the frequency of deoxynucleotide incorporation $\left(f_{\text {inc }}\right)$ and the frequency of extension $\left(f_{\text {ext }}{ }^{0}\right.$ using the following equation: $f_{\text {inc or ext }}=\left(V_{\max } / K_{\mathrm{m}}\right)_{\text {incorrect pair }} /\left(V_{\max } / K_{\mathrm{m}}\right)_{\text {correct pair }}$.

\section{Acknowledgments}

This work was supported by National Institutes of Health research grants GM19261 and GM58534. We thank Tom Wood for sequencing the $\operatorname{can} 1^{r}$ mutations, which work was performed in the Molecular Biology Core Laboratory supported by NIEHS Center Grant P30 ESO6676.

The publication costs of this article were defrayed in part by payment of page charges. This article must therefore be hereby marked 'advertisement' in accordance with 18 USC section 1734 solely to indicate this fact.

\section{References}

Alani, E., Cao, L., and Kleckner, N. 1987. A method for gene disruption that allows repeated use of URA3 selection in the construction of multiply disrupted genes. Genetics 116: 541-545.

Armstrong, J.D. and Kunz, B.A. 1990. Site and strand specificity of UVB mutagenesis in the SUP4-o gene of yeast. Proc. Nat. Acad. Sci. 87: 9005-9009.

Bailly, V., Lauder, S., Prakash, S., and Prakash, L. 1997. Yeast DNA repair proteins Rad6 and Rad18 form a heterodimer that has ubiquitin conjugating, DNA binding, and ATP hydrolytic activities. J. Biol. Chem. 272: 23360-23365.

Bjoras, M., Klungland, A., Johansen, R.F., and Seeberg, E. 1995. Purification and properties of the alkylation repair DNA glycosylase encoded $M A G$ gene from Saccharomyces cerevisiae. Biochem. 34: 4577-4582.

Brash, D.E. 1997. Sunlight and the onset of skin cancer. Trends Genet. 13: 410-414.

Burgers, P.M.J. and Gerik, K.J. 1998. Structure and processivity of two forms of Saccharomyces cerevisiae DNA polymerase ઈ. J. Biol. Chem. 273: 19756-19762.

Canella, K.A. and Seidman, M.M. 2000. Mutation spectra in supF: Approaches to elucidating sequence context effects. Mutat. Res. 450: 61-73.

Creighton, S., Bloom, L.B., and Goodman, M.F. 1995. Gel fidelity assay measuring nucleotide misinsertion, exonucleolytic proofreading, and lesion bypass efficiencies. Methods Enzym. 262: 232-256.

Cuniasse, P., Sowers, L.C., Eritja, R., Kaplan, B., Goodman, M.F., Cognet, J.A.H., LeBret, M., Guschlbauer, W., and Fazakerley, G.V. 1987. An abasic site in DNA. Solution conformation determined by proton NMR and molecular mechanics calculations. Nucl. Acids Res. 15: 8003-8022.

Cuniasse, P., Fazakerley, G.V., Guschlbauer, W., Kaplan, B.E., and Sowers, L.C. 1990. The abasic site as a challenge to DNA polymerase. A nuclear magnetic resonance study of $G, C$, and $T$ opposite a model abasic site. J. Mol. Biol. 213: 303-314.

Drake, J.W. 1991. A constant rate of spontaneous mutation in DNA-based microbes. Proc. Nat. Acad. Sci. USA 88: 7160-7164.

Gerik, K.J., Li, X., Pautz, A., and Burgers, P.M.J. 1998. Characterization of the two small subunits of Saccharomyces cerevisiae DNA polymerase $\delta$. J. Biol. Chem. 273: 1974719755.

Gibbs, P.E.M. and Lawrence, C.W. 1995. Novel mutageneic properties of abasic sites in Saccharomyces cerevisiae. J. Mol. Biol. 251: 229-236.

Giot, L., Chanet, R., Simon, M., Facca, C., and Faye, G. 1997. Involvement of the yeast DNA polymerase $\delta$ in DNA repair in vivo. Genetics 146: 1239-1251.

Goodman, M.F., Creighton, S., Bloom, L.B., and Petruska, J. 1993. Biochemical basis of DNA replication fidelity. Crit. Rev. Biochem. Mol. Biol. 28: 83-126.

Haracska, L., Yu, S.-L., Johnson, R.E., Prakash, L., and Prakash, S. 2000. Efficient and accurate replication in the presence of 7,8-dihydro-8-oxoguanine by DNA polymerase $\eta$. Nature Genet. 25: 458-461.

Haracska, L., Washington, M.T., Prakash, S., and Prakash, L. 2001. Inefficient bypass of an abasic site by DNA polymerase ๆ. J. Biol. Chem. (in press).

Johnson, R.E., Torres-Ramos, C.A., Izumi, T., Mitra, S., Prakash, S., and Prakash, L. 1998. Identification of APN2, the Saccharomyces cerevisiae homolog of the major human AP endonuclease $H A P 1$, and its role in the repair of abasic sites. Genes \& Dev. 12: 3137-3143.

Johnson, R.E., Prakash, S., and Prakash, L. 1999. Requirement of DNA polymerase activity of yeast Rad30 protein for its biological function. J. Biol. Chem. 274: 15975-15977.

Johnson, R.E., Washington, M.T., Haracska, L., Prakash, S., and Prakash, L. 2000a. Eukaryotic polymerases $\iota$ and $\zeta$ act sequentially to bypass DNA lesions. Nature 406: 1015-1019.

Johnson, R.E., Washington, M.T., Prakash, S., and Prakash, L. 2000b. Fidelity of human DNA polymerase $\eta$. J. Biol. Chem. 275: 7447-7450.

Kalnik, M.W., Chang, C.-N., Grollman, A.P., and Patel, D.J. 1988. NMR studies of abasic sites in DNA duplexes: Deoxyadenosine stacks into the helix opposite the cyclic analogue of 2-deoxyribose. Biochem. 27: 924-931.

Kunz, B.A., Henson, E.S., Roches, H., Ramotor, D., Nunoshiba, T., and Demple, B. 1994. Specificity of the mutator caused by deletion of the yeast structural gene $(A P N 1)$ for the major apurinic endonuclease. Proc. Nat. Acad. Sci. 91: 8165-8169.

Lawrence, C.W. and Hinkle, D.C. 1996. DNA polymerase $\zeta$ and the control of DNA damage induced mutagenesis in eukaryotes. Cancer Surveys 28: 21-31.

Lindahl, T. and Nyberg, B. 1972. Rate of depurination of native deoxyribonucleic acid. Biochem. 11: 3610-3617.

Mendelman, L.V., Petruska, J., and Goodman, M.F. 1990. Base mispair extension kinetics. Comparison of DNA polymerase $\alpha$ and reverse transcriptase. J. Biol. Chem. 265: 2338-2346.

Nelson, J.R., Lawrence, C.W., and Hinkle, D.C. 1996a. Deoxycytidyl transferase activity of yeast REV1 protein. Nature 382: 729-731.

1996b. Thymine-thymine dimer bypass by yeast DNA polymerase $\zeta$. Science 272: 1646-1649.

Prakash, L. 1981. Characterization of postreplication repair in Saccharomyces cerevisiae and effects of rad6, rad18, rev3 and rad52 mutations. Mol. Gen. Genet. 184: 471-478.

Roy, R., Brooks, C., and Mitra, S. 1994. Purification and biochemical characterization of recombinant $N$-methylpurineDNA glycosylase of the mouse. Biochem. 33: 15131-15140.

Strauss, B.S. 1991. The 'A-rule' of mutagen specificity: A consequence of DNA polymerase bypass of non-instructional lesions? BioEssays 13: 79-84.

Washington, M.T., Johnson, R.E., Prakash, S., and Prakash, L. 2000. Accuracy of thymine-thymine dimer bypass by Saccharomyces cerevisiae DNA polymerase $\eta$. Proc. Nat. Acad. Sci. 97: 3094-3099.

Yu, S.-L., Johnson, R.E., Prakash, S., and Prakash, L. 2001. Requirement of DNA polymerase $\eta$ for error-free bypass of UV-induced CC and TC photoproducts. Mol. Cell. Biol. 21: 185-188. 


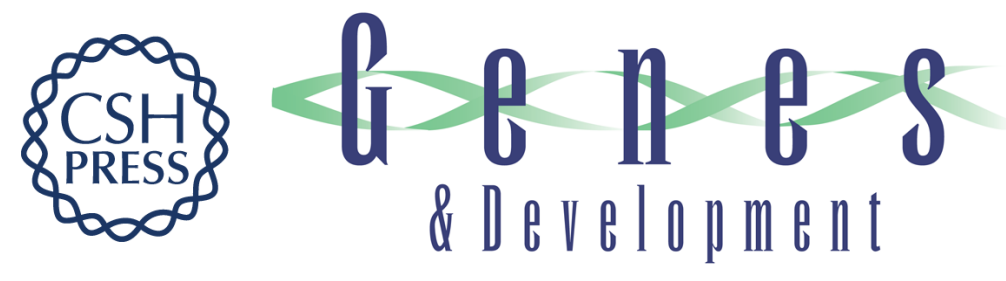

\section{Roles of yeast DNA polymerases $\delta$ and $\zeta$ and of Rev1 in the bypass of abasic sites}

Lajos Haracska, Ildiko Unk, Robert E. Johnson, et al.

Genes Dev. 2001, 15:

Access the most recent version at doi:10.1101/gad.882301

References This article cites 32 articles, 15 of which can be accessed free at: http://genesdev.cshlp.org/content/15/8/945.full.htmI\#ref-list-1

License

Email Alerting

Receive free email alerts when new articles cite this article - sign up in the box at the top Service right corner of the article or click here.

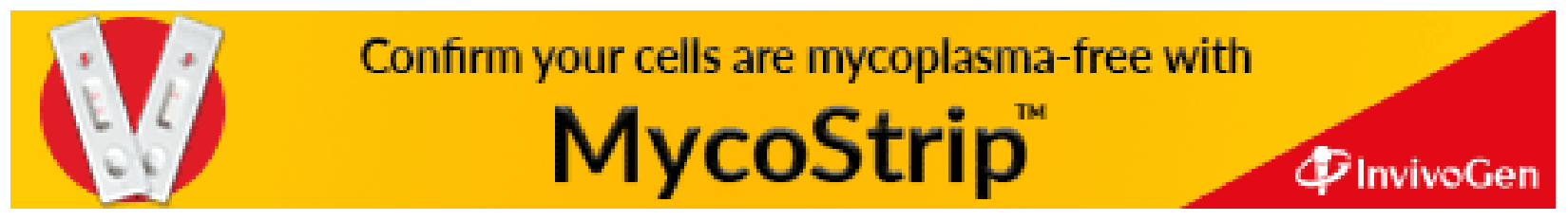

